\title{
High Temperature Oxidation of Some Iron-Chromium Alloys
}

\author{
by D. Caplan and M. Cohen
}

\begin{abstract}
The scaling characteristics of three $\mathrm{Fe}-\mathrm{Cr}$ alloys have been investigated by determining their weight gain vs. time curves at $1600^{\circ}$ to $2000^{\circ} \mathrm{F}$. The scales formed thereby have been examined using the techniques of X-ray diffraction and spectrographic and metallographic analyses in an attempt to explain the discontinuities in the curves and to elucidate the mechanism of scaling.
\end{abstract}

D ESPITE the considerable number of investigations that have been carried out on heat resistant alloys, the characteristics of the scales formed at high temperatures are not fully known. The research reported here was undertaken in an attempt to ascertain the mechanism of scaling of the stainless steels. Scaling experiments were carried out first, the weight increase of the specimens being followed continuously with time. It was observed that, as well as showing the expected decrease in oxidation rate with time, the oxidation curves showed breaks corresponding to intermediate periods of accelerated oxidation, after which protectiveness again increased. This phenomenon was observed with austenitic stainless steels (types 302, 309, and 330) and with $\mathrm{Fe}-\mathrm{Cr}$ alloys (types 410,430 , and 446 ), but only the latter are treated in this report. An examination of the scales was made using the techniques of X-ray diffraction and spectrographic and metallographic analyses in an attempt to obtain a correlation between the nature of the scales and the oxidation curves.

A search through the literature revealed only a very few previous reports of such periods of accelerated oxidation. Dunn ${ }^{1}$ found breaks in the oxidation-time curves of some $\mathrm{Cu}-\mathrm{Si}$ alloys but saw no rational explanation of the phenomenon. Heindlhofer and Larsen ${ }^{2}$ attributed a discontinuity in the weight gain-time curve of iron at $1290^{\circ} \mathrm{F}$ to the formation of blisters, the subsequent cracking of which exposed an unprotected surface and permitted rapid oxidation until a new protective scale had been reestablished. They advanced no explanation, however, for what they termed the peculiar behavior of a 27 pct $\mathrm{Fe}-\mathrm{Cr}$ alloy at $2000^{\circ} \mathrm{F}$ which gained weight very rapidly in between two periods of very slow weight gain. Portevin, Pretet, and Jolivet ${ }^{3}$ in describing breaks in the weight gain-time curves of $\mathrm{Fe}-\mathrm{Al}$ alloys suggested that they might be associated with the occurrence of localized and deeply oxidized

D. CAPLAN and M. COHEN are associated with the Division of Applied Chemistry, National Research Council, Ottawa, Ont., Canada.

Discussion on this paper, TP 3366E, may be sent, 2 copies, to AIME by Dec. 1, 1952. Manuscript, April 3, 1952. Philadelphia Meeting, October 1952.
Table I. Chemical Compositions of Specimen Materials

\begin{tabular}{lccc}
\hline Element, Pct & Type 410 & Type 430 & Type 446 \\
\hline Carbon & 0.10 & 0.10 & 0.20 \\
Manganese & 0.34 & 0.40 & 0.40 \\
Silicon & 0.28 & 0.37 & 0.44 \\
Nickel & 0.21 & 0.43 & 0.32 \\
Chromium & 11.44 & 15.78 & $\mathbf{2 6 . 5 4}$ \\
\hline
\end{tabular}

areas on the specimens. Bandel ${ }^{4}$ in a general discussion of oxidation curves of heat resistant alloys considered that the discontinuities were due to a local disruption of the protective layer by the growth of iron-rich oxides. Day and Smith ${ }^{5}$ in their report on the scaling of a large number of iron alloys noted but did not explain occasional relatively rapid changes in oxidation rate at higher temperatures. Chevenard and Wache ${ }^{8}$ found breaks, often two per specimen, in the oxidation curves of an 18-8 type alloy. They suggested that the cause might be a depletion in chromium of the surface layer of metal due to its selective oxidation, the resultant high concentration of iron and nickel in the scale leading to a poorly protective scale. McCullough, Fontana, and $\mathrm{Beck}^{7}$ explained the breaks in the oxidation curves of types 304,430 , and 410 alloys as due to mechanical ruptures.

\section{Experimental Work}

Table I lists the chemical compositions of the materials used. Cylindrical specimens $1 / 4$ in. in diam and $1 \frac{1}{2}$ in. long were machined from cold rolled $3 / 8$ in. rod. After a fine finish cut with a sharp tool, the specimens were abraded while still mounted on the lathe with Nos. 2, 1, 0, and 00 metallographic grade emery papers. A $3 / 64$ in. hole was drilled at a distance of $1 / 8$ in. from one end to permit suspension in the furnace. Specimen Nos. 1, 2, and 3 were tested with this surface preparation. All others, after being similarly prepared, were electropolished in a perchloric-acetic electrolyte, electrical contact being made by pressing a tapered platinum hook into the drilled hole. The specimens were then washed in hot water, rinsed with distilled water, rinsed with methanol, dried at $120^{\circ} \mathrm{F}$, and weighed. Thereafter, 


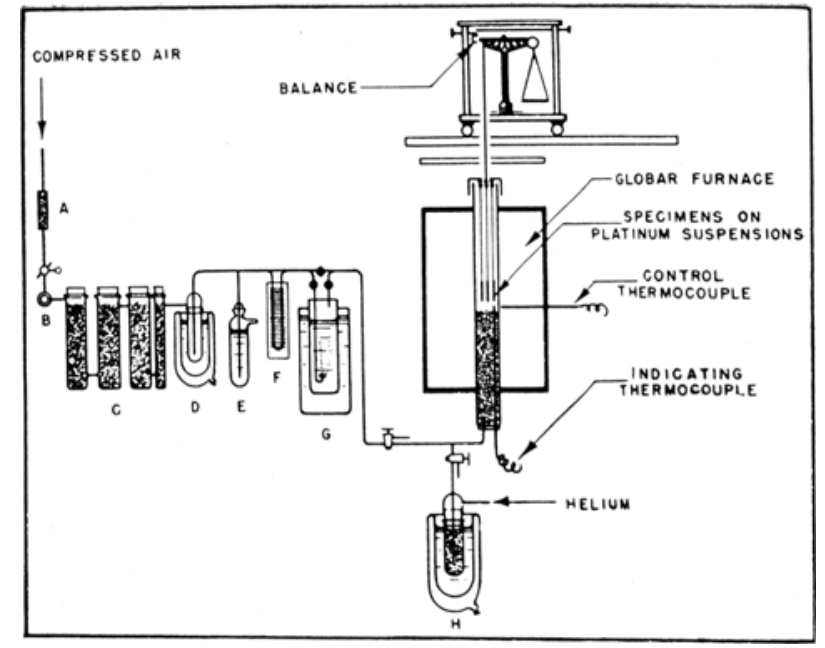

Fig. 1-Diagram of scaling apparatus.

A-Glass wool filter.
B-Reducing valves.
C-Absorption towers of cal-
cium chloride, soda lime,
ascarite, magnesium per-
chlorate.
D-Liquid air trap.
E-Constant pressure regulator
(concentrated sulphuric acid).

F-Flowmeter (n-butyl phthalate).

G-Water saturator in constant temperature bath.

$\mathrm{H}$-Activated charcoal in liquid air trap.

they were handled only with forceps or rubber gloves. Measurements of the length and diameter were made with micrometer calipers and the apparent surface areas calculated.

The apparatus for carrying out the oxidation runs is shown in Fig. 1. Three specimens were suspended by means of platinum wires in a vertical tube furnace of $1 \frac{1}{8}$ in. ID. Temperature measurements were made with a shielded platinum-platinum-rhodium thermocouple located in the tube $1 / 4$ in. below the specimens. The temperature was controlled to within $2^{\circ} \mathrm{F}$ at $2000^{\circ} \mathrm{F}$ by means of a temperature controller actuated by a bare chromel-alumel thermocouple located outside the furnace tube and able to "see" the globar heating elements. The 9 in. heating section of the elements gave a working zone that varied by no more than $1^{\circ} \mathrm{F}$ over the length of the specimens. An analytical balance, protected from the heat of the furnace by interposed baffle plates, was mounted on a rolling table so that it could be located directly over the vertical tube or rolled to one side to permit the introduction or removal of specimens. The method of suspension was such that the three specimens could be weighed alternately at $2 \mathrm{~min}$ intervals. The prepared air stream was admitted to the bottom of the furnace tube at a rate of $200 \mathrm{ml}$ per min, which amounted to a linear rate of flow of $12 \mathrm{in}$. per min in the $1 \frac{1}{8} \mathrm{in}$. ID tube. Packing of the lower part of the tube with ceramic rings served to preheat the air.

Air from a compressed air line at 60 psi was passed through a glass wool filter ( $A$ in Fig. 1) and reduced to $3 / 4$ psi by two reducing valves $(B)$. The greater part of the water and carbon dioxide was removed by calcium chloride, soda lime, ascarite, and magnesium perchlorate in the absorption towers $(C)$; the liquid air trap (D) removed the last traces of moisture and carbon dioxide. The rate of flow was adjusted and controlled by the constant pressure regulator $(E)$, the level of the concentrated sulphuric acid being modified as required to give the desired reading on the flowmeter $(F)$. Some runs were conducted with air prepared and dried in this way. In the others, this dry air was saturated with water vapor at $90^{\circ} \mathrm{F}$ by passing it through the water saturator $(G)$. Provision was also made for flushing the furnace tube with helium purified by passing through activated charcoal held at liquid air temperature $(H)$.

Method of Measurement: After the furnace had been brought to the required temperature and the gas flow adjusted to the correct rate, the three specimens were lowered into the furnace, the balance rolled into position and weighing begun. Zero time was taken as the time of introduction of the specimens. Zero weight was determined by weighing the specimens at room temperature prior to the start of the run and adding the correction $(1.1 \mathrm{mg})$ for the change in buoyant force at the testing temperature.

In an alternative procedure which was used in some of the runs to prevent oxidation during the heating up period, the specimens were brought to temperature in helium. The furnace tube was flushed out with helium at $500 \mathrm{ml}$ per $\mathrm{min}$ for $30 \mathrm{~min}$, the specimens put in, and the initial weight determined, corrections being made for the difference in buoyant force between helium and air $(0.3 \mathrm{mg})$. Zero time was when the helium was turned off and the prepared air stream turned on.

At the end of a run the specimens were removed singly and one end dipped immediately into a button of molten silver. By freezing around the hot specimen this silver prevented the scale from flaking off on cooling and proved useful in the metallographic examination of scales which spalled badly.

Examination of the Specimens: As soon as the silver button described above had solidified, the hot specimen was placed in a quartz dish and examined during cooling by means of a low power stereoscopic microscope for spalling, cracking, color, texture, and inhomogeneities of the scale. In some cases, this was the only way a knowledge of the scale structure could be obtained, since after cooling, the scale might all have disintegrated to a coarse powder. When cold, further examination was made with this microscope and a cross-sectional sketch drawn of the apparent structure. Tiny pieces of the various layers, as uncontaminated as possible with other layers, were picked out under the microscope with a needle and mounted for X-ray diffraction analysis. After

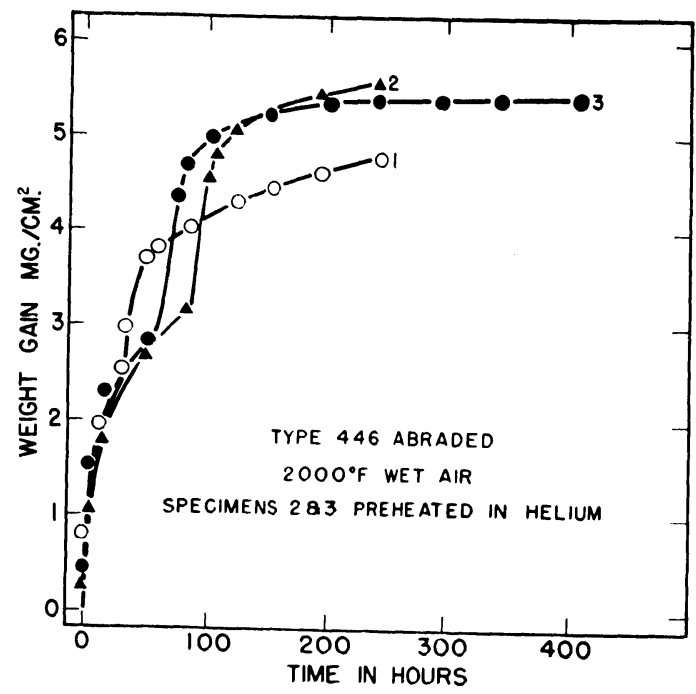

Fig. 2-Oxidation of type 446 stainless steel (abraded) at $2000^{\circ} \mathrm{F}$ in moist air, with and without preheating in helium. 


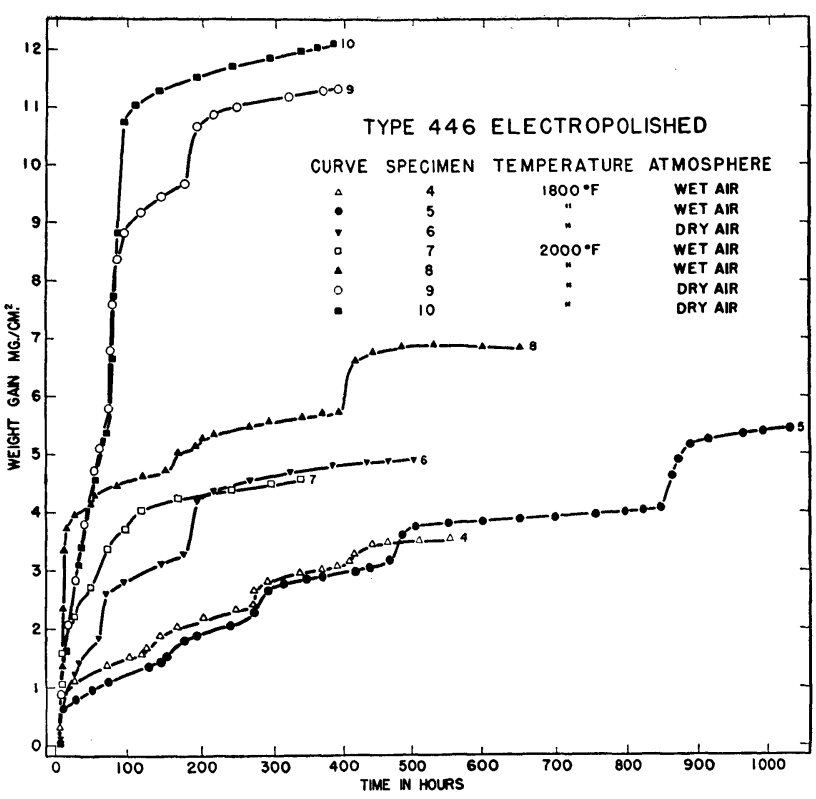

Fig. 3-Oxidation of type 446 stainless steel (electropolished) at $1800^{\circ}$ and $2000^{\circ} \mathrm{F}$ in moist and dry air.

diffraction the same samples were used for spectrographic analysis.

Considerable effort was applied to the development of an impregnation and mounting technique in order that as true a cross section as possible could be prepared for metallographic examination. The method finally adopted was a double vacuum impregnation, first with bakelite lacquer and then with methyl methacrylate monomer. The plastic was kept frozen in a side tube of the vacuum apparatus while the system was evacuated, then warmed and allowed to flow over the specimen. By first coating the whole specimen with the lacquer, the scale was prevented from breaking up when the microspecimens were sawed out. The less viscous monomer then penetrated along the tiny passages from the cut edges. After polymerizing the monomer with slow heating to prevent the formation of vapor bubbles within the scale, the specimens could be mounted as usual in molding powder. Wet grinding and polishing with silicon carbide and diamond instead of with the softer abrasives gave less relief polishing of the extremely hard oxide layers and less rounding of the edges. Polarized light was used in the metallographic examination to distinguish between isometric and nonisometric oxide crystals.

\section{Results}

Scaling Runs: The weight gain vs. time curves in moist air at $2000^{\circ} \mathrm{F}$ of three type 446 (27 pct $\mathrm{Cr}$ ) abraded specimens are shown in Fig. 2. In order to make the graphs less confusing many of the experimentally determined points have been omitted from Figs. 2, 3, and 4. Specimen No. 1 was introduced into the furnace with the air stream flowing, while Nos. 2 and 3 were brought to temperature in helium. This latter procedure was not used for any of the subsequent runs, since it was observed that the specimens slowly lost weight ( $2 \mathrm{mg}$ in $30 \mathrm{~min}$ ) during the helium pretreatment. Austenitic alloys tested at the same time slowly gained weight during this period ( $1 \mathrm{mg}$ for type 302 and $0.5 \mathrm{mg}$ for type 309 ) indicating that a small amount of oxidizing gas was present, due possibly to moisture in the furnace tube or ceramic packing rings.
Fig. 3 shows the oxidation curves of seven type 446 electropolished specimens. These represent runs carried out at $1800^{\circ}$ and $2000^{\circ} \mathrm{F}$, in dry and in moist air. The very coarse time scale necessarily used in plotting Figs. 2 and 3 tends to misrepresent the high degree of protectiveness of the scales in the periods between the breaks. For instance, the apparently steep flat before the last break in curve No. 9 denotes a weight gain of only $1.4 \mathrm{mg}$ per specimen per day, and a more protective flat, such as the one before the last break in curve No. 5, a gain of only $0.15 \mathrm{mg}$ per specimen per day. The addition of moisture leads to an unexpected result: at $1800^{\circ} \mathrm{F}$ specimens 4 and 5 , in moist air, gained less weight than No. 6, in dry air, and at $2000^{\circ} \mathrm{F}$ Nos. 7 and 8, in moist air, gained less than Nos. 9 and 10, in dry air. This is at variance with previous work which has shown ${ }^{8-10}$ that the addition of moisture to the oxidizing atmosphere results in increased oxidation (except for two cases $^{11,12}$ where the experiments were carried out at quite low temperatures).

Comparison of curves 7 and 8 in Fig. 3 with the curves in Fig. 2 indicates that the surface preparation used for the specimens is unimportant, probably because the conditions of oxidation are too severe for this relatively minor variable to have an effect.

Fig. 4 shows the oxidation curves of four type 410 (12 pct $\mathrm{Cr}$ ) and 430 (16 pct $\mathrm{Cr}$ ) electropolished specimens at $1600^{\circ} \mathrm{F}$ in moist and in dry air. In contrast to type 446 at $1800^{\circ}$ and $2000^{\circ} \mathrm{F}$, these specimens show a greater weight gain in moist air than in dry. Breaks appear in the curves but are not of the same type as those in Figs. 2 and 3. The nature of these breaks and the effect of moisture are treated in the discussion.

Examination of Scales on Type 446: Fig. 5 is a representation of a typical scale cross section on the 27 pct $\mathrm{Cr}$ alloy as estimated from the stereoscopic microscope examination. (Specimen 8 is the scale actually drawn.) There is an outer black layer or in some cases two such layers ( $A$ and $C$ ) finely wrinkled, poorly adherent, and fragile. Beneath this is a greenish-black, glassy layer $(E)$, very hard and

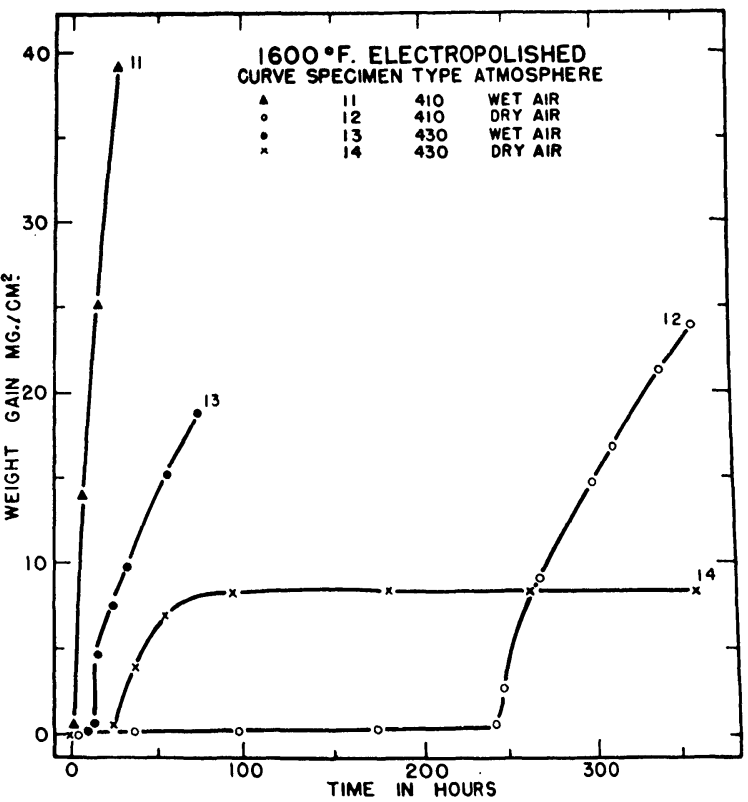

Fig. 4-Oxidation of types 410 and 430 stainless steels (electropolished) at $1600^{\circ} \mathrm{F}$ in moist and dry air. 


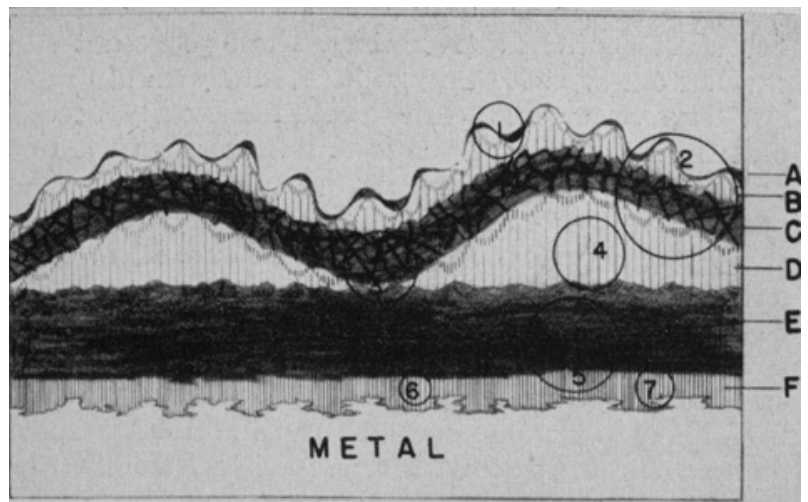

Fig. 5-Type 446. Specimen 8. Diagrammatic representation of scale cross section. Layers $B, D$, and $F$ are silica. Layers $A$ and $C$ mostly spinel. Layer $\mathrm{E}$ mostly $\mathrm{Cr}_{2} \mathrm{O}_{3}$. The numbered circles show where samples were taken for $\mathrm{X}$-ray diffraction and spectrographic analysis. See Table II.

abrasion resistant. White crystals ( $B$ and $D$ ) exist between all the scale layers and between the scale and the metal $(F)$. The crystals between the outer layers are usually masses of tiny needles, sometimes with white or gray granular material as well. The crystals between the scale and the metal are in the form of a rough crumbly grayish-white layer, some of which is adherent to the metal and some to the underside of the glassy layer. At higher magnifications tiny metallic spheres can be seen embedded in this layer $F$.

The accuracy of the spectrographic analysis is low because the samples used only weighed from 0.01 to $0.1 \mathrm{mg}$; these very small amounts of any one fraction uncontaminated with other fractions were all that could be separated under the microscope. The analyses show that the scales are made up mainly
Table II. Analyses of Scale Layers on Specimen 8

\begin{tabular}{ccrrrr}
\hline & & \multicolumn{3}{c}{ Diffraction Data* } \\
\cline { 3 - 6 } Fraction & Layer & $\begin{array}{c}\text { Spinel } \\
\left(\mathbf{M}_{3} \mathbf{O}_{4}\right)\end{array}$ & $\begin{array}{c}\text { Rhombo- } \\
\text { hedral } \\
\left(\mathbf{M}_{2} \mathbf{O}_{3}\right)\end{array}$ & Silica & Metal \\
\hline & A, B & 100 & 0 & 20 & 0 \\
1 & A, B, C, D & 100 & 10 & 40 & 0 \\
$\mathbf{3}$ & C & 100 & 30 & 0 & 0 \\
4 & D & 20 & 5 & 100 & 0 \\
$\mathbf{5}$ & E, F & 1 & 100 & 60 & 0 \\
6 & F & 15 & 25 & 100 & 40 \\
7 & F & 20 & 15 & 100 & 50 \\
\hline
\end{tabular}

* The numerical values are the relative intensities of the strongest lines in each of the four patterns.

of chromium oxide with silica the next largest constituent. Iron and manganese are present in lesser amounts. Aluminum and copper are detectable but nickel is not. The ratio of chromium to iron is about 20 to 1 .

The numbered circles on Fig. 5 represent where samples were taken for X-ray diffraction and spectrographic analysis; the areas falling within the circles indicate the anticipated contaminants of each fraction. Table II shows the X-ray diffraction data for these fractions.

The diffraction data show that the scales on the 27 pct $\mathrm{Cr}$ alloy oxidized either at $1800^{\circ}$ or $2000^{\circ} \mathrm{F}$, in moist or in dry air, are made up of four phases:

$1-\mathrm{A}$ spinel of lattice parameter about $8.40 \AA$ which, considering the accuracy of the technique, fits either of the spinels $\mathrm{Fe}_{3} \mathrm{O}_{4}$ (8.40), $\mathrm{FeO} \cdot \mathrm{Cr}_{2} \mathrm{O}_{3}$ (8.35), or $\mathrm{MnO} \cdot \mathrm{Cr}_{2} \mathrm{O}_{3}$ (8.42), all of which are possible on the basis of the spectrographic analysis.

2-A rhombohedral oxide, the diffractogram fitting $\alpha \mathrm{Fe}_{2} \mathrm{O}_{3}$ or $\mathrm{Cr}_{2} \mathrm{O}_{3}$ or solid solutions of these two.

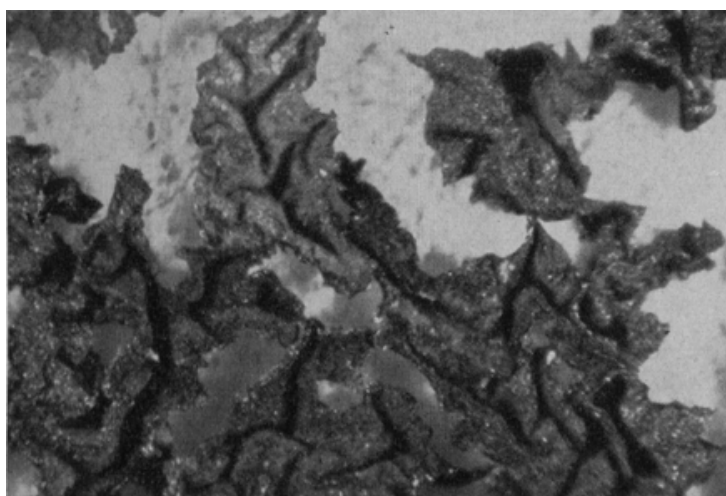

Fig. 6-Type 446. Specimen 5. Flaked-off pieces of outer layer of scale showing extensive wrinkling and gray silica clinging to underside. $X 50$.

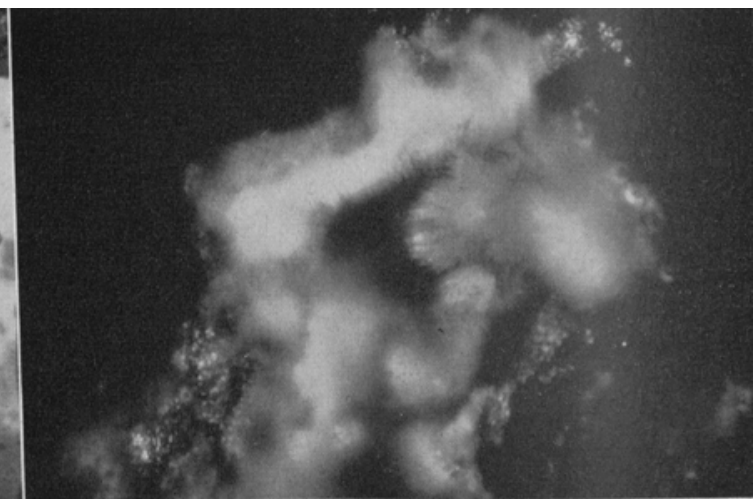

Fig. 7-Type 446. Specimen 10. Underside of outer scale layer showing needle-like silica crystals. X250.

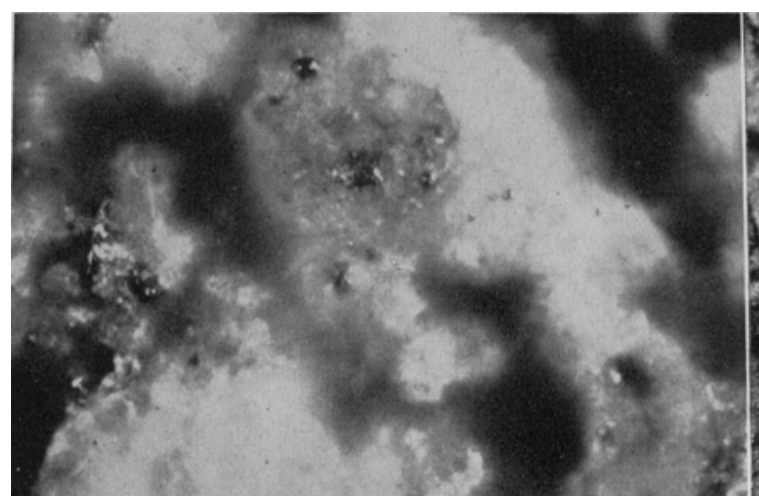

Fig. 8-Type 446. Specimen 7. Metallic spheres embedded in the silica layer adhering to the metal specimen. Compare with Fig. 10. X750.

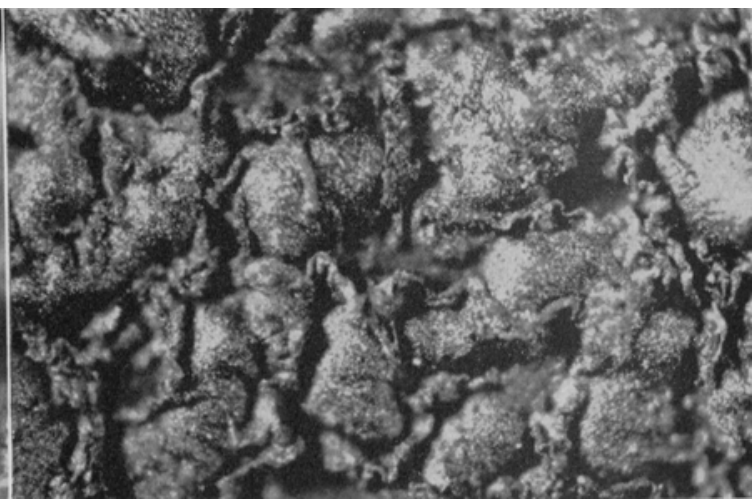

Fig. 9-Type 446. Specimen 7. Plan view of outer side of outer layers of scale showing severely wrinkled layer lying in troughs of undulating layer. Compare with Fig. 10 . X90. 
An attempt was made to determine the approximate composition by comparing the relative line intensities with those reported in the literature ${ }^{13,14}$ and with the patterns obtained from known $\alpha \mathrm{Fe}_{2} \mathrm{O}_{3}$ and $\mathrm{Cr}_{2} \mathrm{O}_{3}$ but without success. The difference in relative line intensities between $\mathrm{Fe}_{2} \mathrm{O}_{3}$ and $\mathrm{Cr}_{2} \mathrm{O}_{3}$ was found to be too small for our purpose.

3 -Silica in the $\alpha$-cristobalite form.

4-Elemental metal which, according to the diffraction pattern, could be iron, chromium, or the $\mathrm{Fe}-\mathrm{Cr}$ alloy.

The outer black wrinkled layer, or layers, is made up of spinel and rhombohedral oxide. The dark green glassy layer is mainly rhombohedral. The white or gray material is $\alpha$-cristobalite, whether it appears as needles or granules. The pattern of elemental metal appears in fractions containing the tiny metallic spheres, layer $F$ in Fig. 5.

The scale structures on the 27 pct $\mathrm{Cr}$ alloy are illustrated in Figs. 6 to 13. The fact that many of the scales spalled badly on cooling made it difficult to obtain good metallographic cross sections and, while the silver button technique was useful for specimens which spalled completely, it was only partly successful since it crushed the fragile outer layers considerably. In many of the cross sections the scale is separated from the metal by a gray layer of methacrylate plastic. This separation probably resulted from the differential contraction of scale and metal on cooling. The dark areas seen in some of the figures are holes where the plastic did not completely fill the voids.

Because the optical contrast between the silica and plastic is low and the needle-like silica crystals are extremely fragile, silica is poorly depicted in the cross sections. It can be faintly discerned as a layer against the metal in Figs. 10 to 13 and, on the microscope, the silica needles under the outer layers can be detected by focusing down into the plastic. The plan views in Figs. 6 to 8 give a truer impression of the large masses of silica present. Metallic spheres similar to those which appear in the silica in Fig. 8 can be seen in cross section adjacent to the metal in Figs. 10 to 13. Their location indicates that they are the remains of intergranularly oxidized grains.

The marked wrinkling of the outer layer is shown in plan in Figs. 6 and 9 and in section in Figs. 10 to 13. The wrinkled layer lying in the troughs of an undulating layer in Fig. 9 is seen in cross section in Fig. 10.

Fig. 11 of specimen 10 shows an outer wrinkled layer, the glassy inner layer, silica against the metal and clinging to the underside of the glassy layer, and the metallic spheres in this silica. The silica needles under the outer layer can only be detected by focusing down into the plastic. The local enlargement included in this field is seen at higher magnification in Fig. 12a and in polarized light in Fig. 12b. The glassy layer is seen to be optically active, indicating $\mathrm{Cr}_{2} \mathrm{O}_{3}$, except for the grayer islands in it. This optical activity of the lighter scale and inactivity of the grayer scale was observed generally not only with type 446 but with types 410 and 430 as well.

Examination of Scales on Types 410 and 430: Examination of the scaled specimens of the 12 and 16 pct $\mathrm{Cr}$ alloys with the stereoscopic microscope shows them to be markedly different from the 27 pct $\mathrm{Cr}$ alloy. There is no evidence of any white crystals; except for an occasional local area, the outer surface is not wrinkled; and the scales are generally redder than those on the type 446 speci-

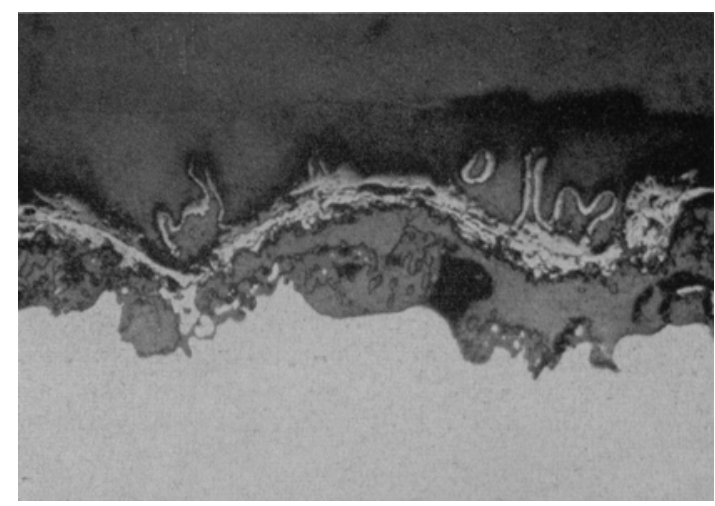

Fig. 10-Type 446. Specimen 7. Metallographic cross section of same scale as Fig. 9 showing severely wrinkled layer lying in troughs of undulating layer. Compare with Fig. 9. Note also silica between metal and scale and remains of intergranularly corroded metal grains in this silica. Unetched. X250.

mens, indicating a higher iron content. The scales are stratified but not as on type 446 ; the layers are more like those which form on unalloyed iron., ${ }^{35-18}$

The structure of the scales on these lower chromium alloys is shown in Figs. 14 to 16 . It can be seen that the scale in contact with the metal is the reduced, gray, optically inactive ( $\mathrm{Fe}, \mathrm{Cr})_{3} \mathrm{O}_{4}$ form, while that in contact with the air has been oxidized to the whiter, optically active, rhombohedral (Fe, $\mathrm{Cr})_{2} \mathrm{O}_{3}$ form.

\section{Discussion}

Comparison of the oxidation curves and scale structures indicates that the character of the oxidation process for the 27 pct $\mathrm{Cr}$ alloy is different from that of the lower chromium alloys. A different scaling mechanism is proposed for each case.

Scaling Mechanism for Type 446: It is evident from the examination of the scales on type 446 stainless steel that silica as a separate phase is a major constitutent, even though the silicon content of the original alloy is only 0.44 pct. Silicon has long been recognized along with chromium and aluminum as one of the elements which contribute oxidation resistance to metals. Oxides of chromium and aluminum, because they can combine with iron oxides

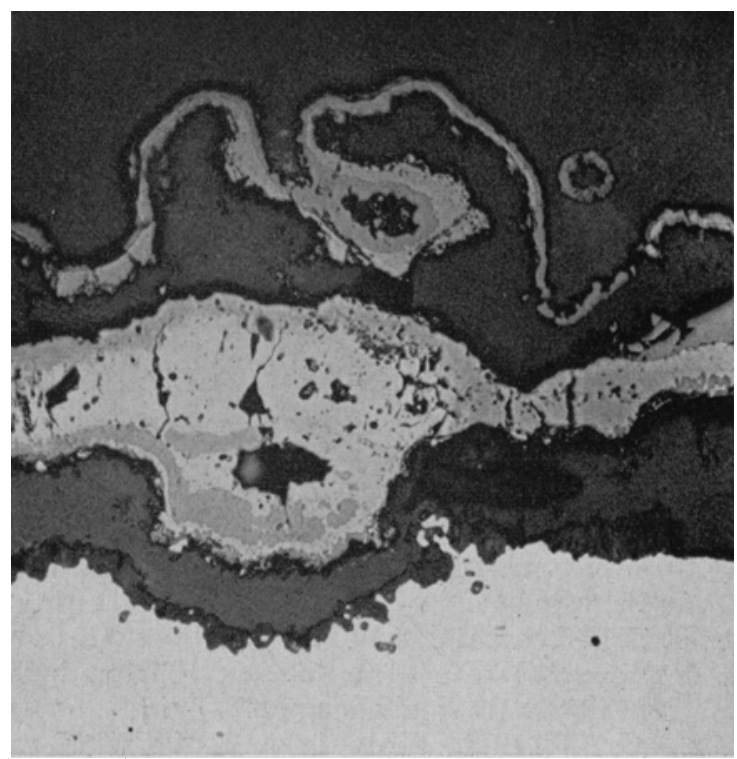

Fig. 11-Type 446. Specimen 10. Metallographic cross section of the scale layers, the field including a local enlargement of the glassy layer. Note extensive wrinkling of outer layer. Unetched. X250. 


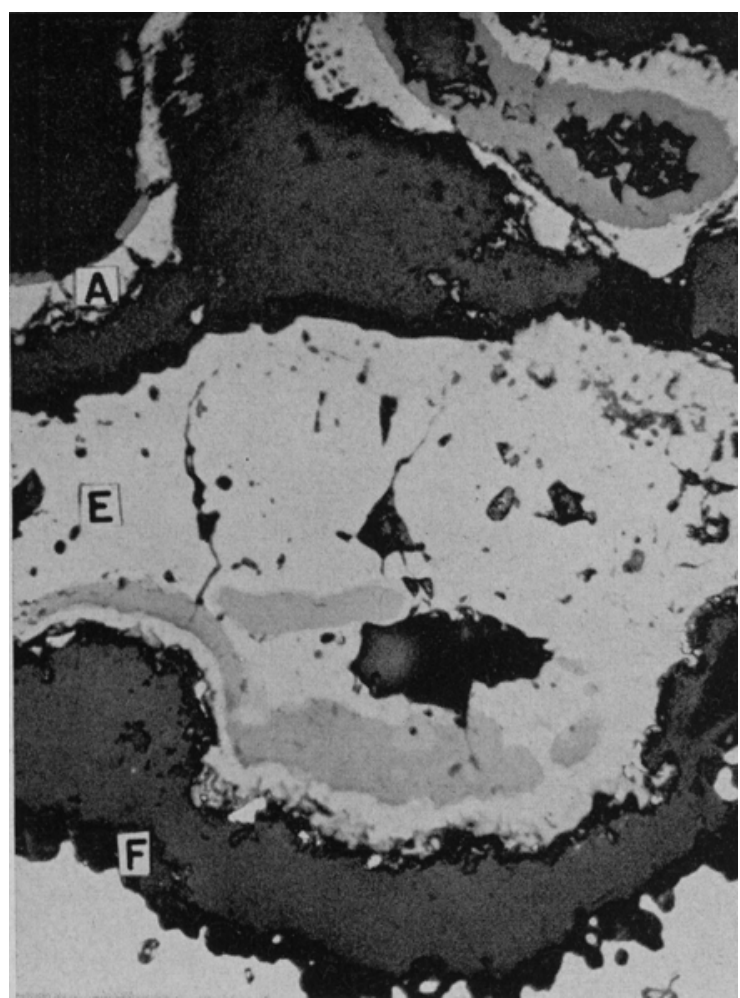

Fig. 12-Part of Fig. 11 at higher magnification. Unetched. $\times 500$.

a-Showing silica layer (F) against metal and clinging to underside of glassy layer, remnants of metal grains in both these silica areas, darker gray islands in highly reflecting glassy loyer (E). Letters correspond to lettered layers of sketch shown in Fig. 5.

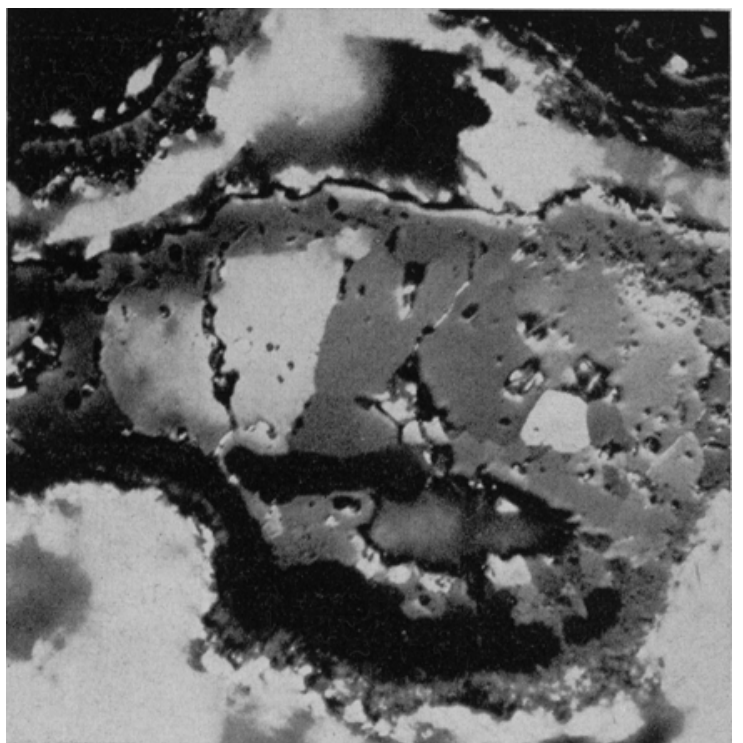

b-Same field in polarized light showing optical activity of glassy layer, indicating $\mathrm{Cr}_{2} \mathrm{O}_{3}$, and inactivity of darker gray islands in glassy layer, indicating isometric oxide.

to form either mixed oxides by isomorphous substitution or spinels, ${ }^{10,20}$ affect the mechanical properties or the electrical conductivity of the scales and thus decrease the rate of oxidation. Silicon, however, does not form such complex oxides nor is fayalite, $\mathrm{Fe}_{2} \mathrm{SiO}_{4}$, detectable in any of the X-ray diffraction patterns. It follows, therefore, that silicon must confer protectiveness in some other way.

The numerous reports in the literature of improvement in oxidation resistance due to the presence of silicon in the metal ${ }^{8-5,21-25}$ have not shown direct evidence of the mechanism by which this improvement is effected. In some instances ${ }^{1,3,22,23,{ }^{26}}$ silica has been observed to concentrate at the metal/scale interface. Dovey and Jenkins ${ }^{22}$ and Hickman and Gulbransen ${ }^{23}$ concluded that the silicon in $\mathrm{Ni}-\mathrm{Cr}$ alloys did not change the bulk structure of the oxides but affected the metal/scale boundary. Griffiths ${ }^{8}$ and Lustman ${ }^{25}$ ascribe an improvement in scale adhesion and consequently in oxidation resistance to the roughness of the metal/scale interface resulting from the oxidation of silicon.

In the case of the scales on type 446 stainless steel which have been examined here, the authors believe the part played by the silica to be as follows:

Fig. 17 is an idealized oxidation curve of the 27 pct $\mathrm{Cr}$ alloy similar to the curves of Figs. 2 and 3.

1 -In the first stage of the oxidation process, represented by section $O A$, a scale of chromium oxide containing minor amounts of iron oxide builds up and the rate falls off parabolically as the film increases in thickness.

2-In section $A B$ silica gradually accumulates between metal and scale, silicon apparently being capable of reducing chromium oxide under the conditions obtaining, and also being insoluble in the chromium oxide lattice. This is in agreement with the data of Lustman ${ }^{27}$ who shows that the dissociation pressure of silica is lower than that of chromium oxide over the full range of temperatures. As a result of this accumulation of silica the transfer of cations across the metal/scale interface is impeded and consequently the rate of oxidation decreases more rapidly than would be predicted by the parabolic law, which is the result of the rate being con-

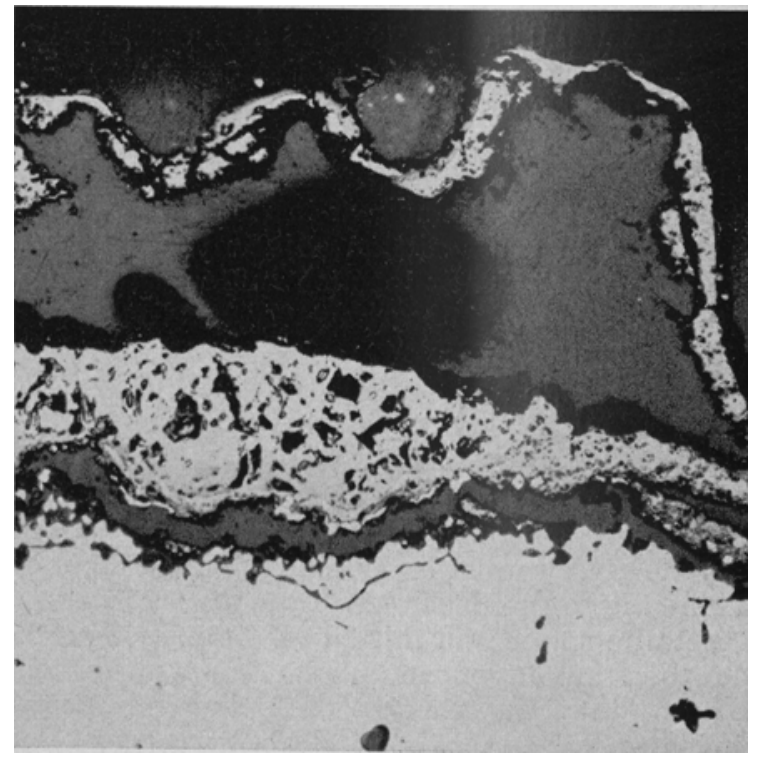

Fig. 13-Type 446. Specimen 9. Note wrinkled outer layer, silica against metal, intergranularly corroded metal and gray (non-optically active) band in main scale layer. Unetched. $\times 250$.

trolled by the diffusion reaction through the scale layer. This leads to the very low weight gains observed during these periods.

3 -As the quantity of silica increases with time, the degree of insulation of the scale from the metal becomes so great that (a) cations are no longer being supplied to the scale, enabling the state of oxidation of the scale to increase to an equilibrium value, and (b) the scale, no longer constrained by attachment to the metal, wrinkles under the force of the 


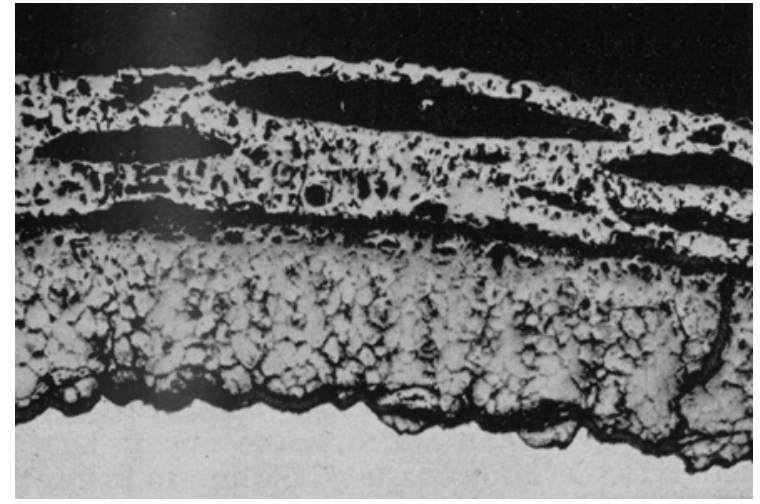

Fig. 14-Type 410. Specimen 11. Showing layered structure of scale of a type more like scale on unalloyed iron than on the type 446 specimens. Note whiter (optically active) outer portion of outer layer indicating $\left(\mathrm{Fe}, \mathrm{Cr}_{2} \mathrm{O}_{3}\right.$. Unetched. $\mathrm{X} 100$.

compressive stresses resulting from the fact that the natural area of the scale is greater than the area of metal surface on which it grows. For either or both of these reasons cracks form in the scale and oxygen is permitted to penetrate to the bare metal underneath. The rate of oxidation now increases sharply as indicated in section $B C$.

4 -Section $C D$ represents the building up of a second layer of scale, essentially chromium oxide again, underneath the outer layer of scale, now wrinkled, and under the silica layer. Section $C D$ is thus equivalent to section $O A$.

5-Another layer of silica accumulates with time, insulates the new scale layer from the substrate, section $D E$, and the break is repeated.

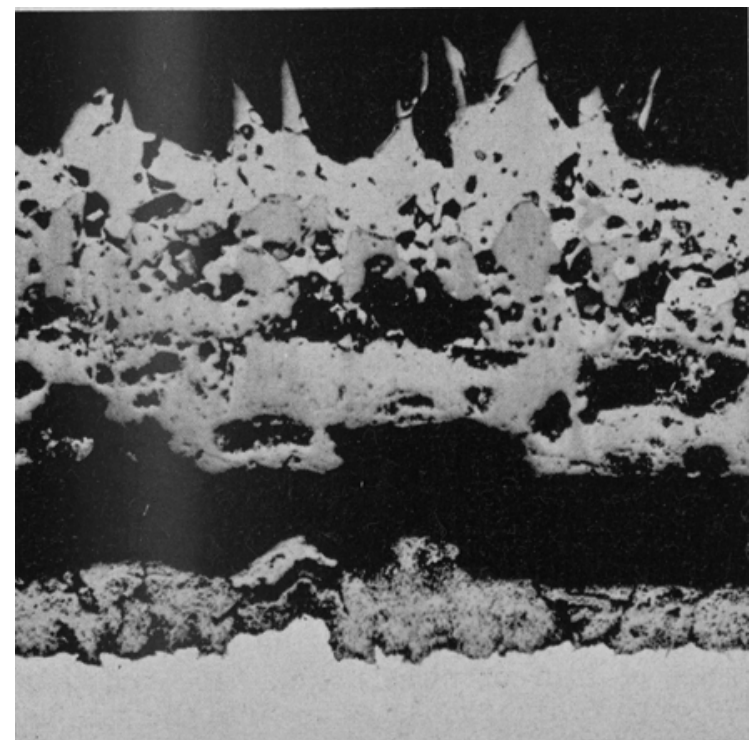

Fig. 15-Type 410. Specimen 12. Showing white $(\mathrm{Fe}, \mathrm{Cr})_{2} \mathrm{O}_{3}$ outer portion of outer layer. Note faceted crystalline outer surface. Unetched. X250.

This mechanism accounts for the mass of silica observed between all the scale layers in the examination of the scales on type 446 and for the fact that the outer layers are greatly wrinkled and cracked and the inner one still monolithic.

The number of layers of scale as seen in the metallographic cross section of a specimen would be expected to correspond to the number of breaks in the oxidation curve and in a number of cases they do, but in the others the number of layers is less than

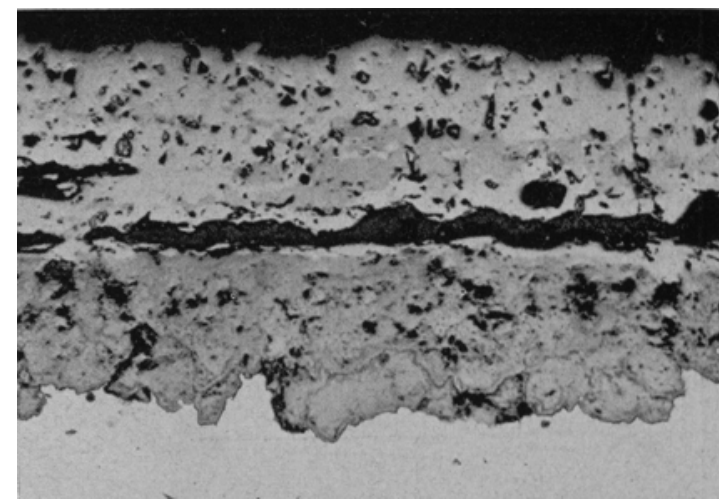

Fig. 16-Type 430. Specimen 13. Showing layered structure after the fashion of scale on unalloyed iron. Outer layer is mostly $(\mathrm{Fe}, \mathrm{Cr})_{2} \mathrm{O}_{3}$ (optically active) except for darker islands.

Outer surface of inner layer is $(\mathrm{Fe}, \mathrm{Cr})_{2} \mathrm{O}_{3}$. Unetched. X250.

the number of breaks. This may be accounted for by assuming that the scale becomes unprotective over only a part of the specimen at a time. In the duplicate specimens 9 and 10 (Fig. 3) it appears that No. 9 broke in two steps while No. 10 became unprotective over the entire specimen at one time. In the case of the lower chromium alloys the number of layers is often more than the number of breaks (if breaks can be spoken of as existing at all) but these extra layers are due to the stratification normal to the scale on unalloyed iron rather than the result of insulation by silica.

Another deduction from the mechanism of the breaks as outlined here is that the thickness or mass of the various layers in a specimen should be proportional to the heights of the breaks or, more correctly, to the vertical distances between the ends of the protective periods. That is, in Fig. 17 the ratio of the mass of the outer layer to that of the next layer should be proportional to the ratio of $x$ to $y$. Estimation of the relative masses is difficult because of the wrinkling and disintegration of the outer layers but it does appear that the outer layer is usually less massive than the ratio of break heights would predict. Two reasons may be advanced to resolve this apparent diversity: 1-A larger proportion of the weight gain indicated for the first layer may have gone into internal oxidation than for the later layers, and 2-the outer layer loses mass by the volatilization of chromium as discussed later.

Scaling Mechanism for Types 410 and 430: The discontinuities in the oxidation curves of the lower chromium alloys (Fig. 4) are of a different type from those of the 27 pct $\mathrm{Cr}$ alloy. Whereas the type 446 specimens (oxidized at $1800^{\circ}$ and $2000^{\circ} \mathrm{F}$ ) initially gained weight rapidly before developing a protective layer, the 12 and 16 pct $\mathrm{Cr}$ specimens (oxidized at $1600^{\circ} \mathrm{F}$ ) show an extraordinarily low initial rate; the break in the curves is due to the departure from this low rate. Evidently, for $\mathrm{Fe}-\mathrm{Cr}$ alloys containing 12 pct $\mathrm{Cr}$ or more, the thin oxide film which forms at low temperature, and which is already present at the beginning of the run, is exceptionally protective and is able to remain so at $1600^{\circ} \mathrm{F}$ for some time (the scale on specimen $12 \mathrm{re}$ mained in this highly protective condition for 240 $\mathrm{hr}$ ). This thin film is a combination of the oxides formed by the electropolishing process, room temperature air oxidation, and oxidation while the specimens are heating up in air to the testing temperature. When this film is destroyed, either by 


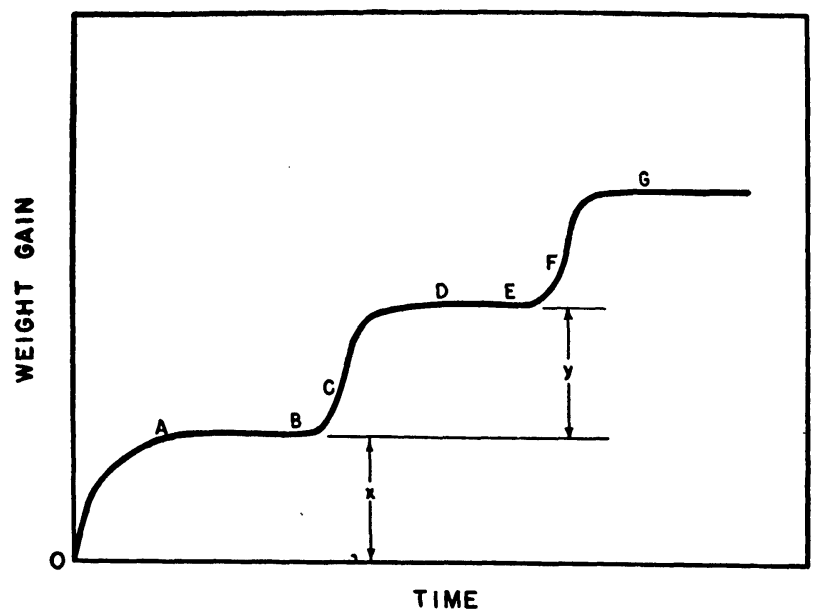

Fig. 17-Idealized oxidation curve for type 446 alloy.

mechanical rupture or by recrystallization or by a change in composition (by dilution with different cations from the metal), the specimens gain weight at the faster rate normal to the testing conditions to which they are exposed until the thickening oxide layer causes the rate to decrease again in accordance with the now generally accepted theory. ${ }^{28}$ Since it is to be expected that the type 446 alloy forms a low temperature film at least as protective as that on the lower chromium alloys, and yet the type 446 specimens do not display this initial exceptional degree of protectiveness (at $1800^{\circ}$ and $2000^{\circ} \mathrm{F}$ ), it follows that the thin film, although protective at $1600^{\circ}$, is unable to protect at $1800^{\circ}$ and $2000^{\circ} \mathrm{F}$. Further, the low temperature film on the lower chromium alloys is probably of the same type and composition as that on the 27 pet $\mathrm{Cr}$ alloy.

Effect of Moisture: A possible explanation of the anomalous effect of moisture on the scaling rate of the 27 pct $\mathrm{Cr}$ alloy can be based on a consideration of the defects in the oxide lattice. It has been shown ${ }^{29}$ by electrical conductivity measurements that $\mathrm{Cr}_{2} \mathrm{O}_{3}$ is a metal deficiency conductor and that the greater the number of cation vacancies, the faster will be the rate of cation diffusion. ${ }^{30}$ If hydrogen ions resulting from the decomposition of water molecules on the scale surface were to occupy some of the vacancies, the diffusion rate and hence the scaling rate would be lessened. On the other hand, $\mathrm{Fe}_{2} \mathrm{O}_{3}$ is a metal-excess oxide. ${ }^{20}$ Therefore, the more iron in

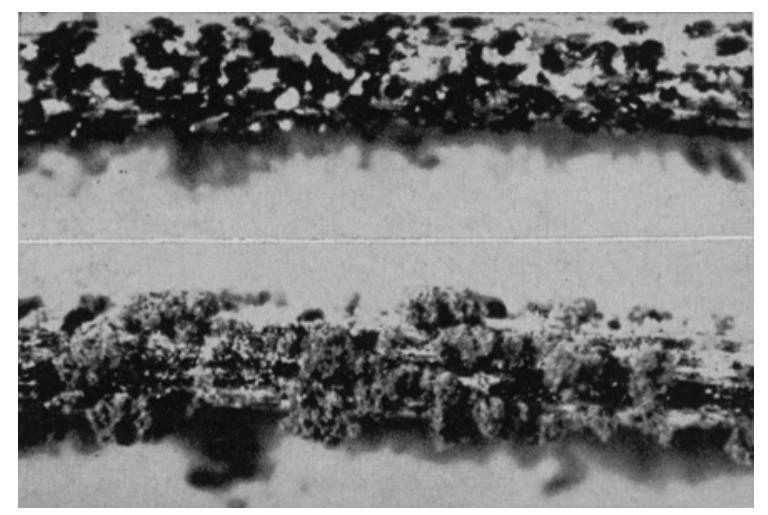

Fig. 18-Sections of platinum suspension wire from specimen 8. $\mathrm{X} 40$.

a (top)-Section showing mostly $\mathrm{Cr}_{2} \mathrm{O}_{3}$ crystals.

b (bottom)-Section closer to specimen (and therefore at higher temperature) showing mossy growth of platinum as well as $\mathrm{Cr}_{2} \mathrm{O}_{3}$ crystals. the $(\mathrm{Fe}, \mathrm{Cr})_{2} \mathrm{O}_{3}$ oxide the less cation deficient the lattice will be. For the lower chromium specimens then, where the relatively rapid scaling rate leads to a higher iron content in the scale, the diffusion rate should be little affected by hydrogen ions and the normal increase in oxidation rate with the addition of moisture can be expected, as is seen in Fig. 4.

Composition of the Spinel Phase: The spinel-type oxide which forms a major part of the scale on the 27 pct $\mathrm{Cr}$ alloy is shown by the spectrographic analysis to have a very high chromium to iron ratiofrom 15 to 1 to as high as 30 to 1 . The spinel chromite, $\mathrm{FeO} \cdot \mathrm{Cr}_{2} \mathrm{O}_{3}$, which is the one to be expected on $\mathrm{Fe}-\mathrm{Cr}$ alloys, has a chromium to iron ratio of only about 2 to 1 . Therefore, the spinel observed must either be $\mathrm{Cr}_{3} \mathrm{O}_{4}$, which the known instability of chromous ion makes improbable, or a spinel structure with additional divalent lattice sites vacant. This is equivalent to a $\gamma$ form of $\mathrm{Cr}_{2} \mathrm{O}_{3}$ analagous to $\gamma \mathrm{Fe}_{2} \mathrm{O}_{3}$, which is a known low temperature oxidation product of iron and which has a diffraction pattern practically indistinguishable from that of $\mathrm{Fe}_{3} \mathrm{O}_{4}$. However, $\gamma \quad \mathrm{Cr}_{2} \mathrm{O}_{3}$ has not been previously described, although this difficulty of a spinel-type structure associated with a high chromium content has been encountered before. ${ }^{71}$

Volatilization of Chromium: As noted above, type 446 specimens lost weight while soaking in helium, whereas austenitic alloys under the same conditions slowly gained weight. It was observed, also, that at the end of a run the platinum suspension wires were discolored, and, in longer runs, were coated with dark green crystals as shown in Fig. 18. X-ray diffraction and electrographic analysis showed these to be $\mathrm{Cr}_{2} \mathrm{O}_{3}$. Since similar crystals were observed on the wall of the furnace tube, it is apparent that chromium has in some way been transported away from the specimens through the gas phase. A calculation based on thermodynamic data given by Dushman $^{32}$ shows that a sublimation process as suggested by Bandel ${ }^{4}$ cannot nearly account for the quantities of $\mathrm{Cr}_{2} \mathrm{O}_{3}$ observed on the wires and tube. However, by estimating the amount of carbon lost from a specimen from the depth of the decarburized ring seen in the metallographic cross section, it can be shown that more than sufficient chromium could be volatilized from the specimen as a result of the decarburization reaction:

$$
\mathrm{Cr}_{2} \mathrm{O}_{3}+3 \mathrm{C} \rightleftarrows 2 \mathrm{Cr}+3 \mathrm{CO}
$$

which has recently been discussed by Gulbransen, Wysong, and Andrew. ${ }^{33}$ The vapor pressure of elemental chromium is relatively high at $2000^{\circ} \mathrm{F}$ (approximately 1 micron $^{32}$-about 100 times the vapor pressure of iron or nickel) and, once reduced, a sufficient percentage might escape into the gas phase before being reoxidized.

\section{Summary}

1-The oxidation of a 12,16 , and 27 pet $\mathrm{Cr}$ stainless steel is studied in dry and in moist air, the 12 and 16 pct alloy at $1600^{\circ} \mathrm{F}$ and the 27 pct at $1800^{\circ}$ and $2000^{\circ} \mathrm{F}$. The oxidation curves of the 27 pct alloy are found to exhibit periods of accelerated oxidation intermediate between periods of high protectiveness. Examination of the scales indicates that this may be due to the accumulation of silica at the scale/metal interface.

Discontinuities in the oxidation curves of the 12 and 16 pct $\mathrm{Cr}$ alloys result from the extraordinary protectiveness (at $1600^{\circ} \mathrm{F}$ ) and subsequent destruc- 
tion of the thin oxide film which forms at low temperature.

2-The 27 pct $\mathrm{Cr}$ specimens unexpectedly gain more weight in dry than in moist air. This may be due to the filling of cation vacancies in the $\mathrm{Cr}_{2} \mathrm{O}_{3}$ lattice with hydrogen ions.

3 -The scale on the 27 pct $\mathrm{Cr}$ alloy is mainly chromium oxide, with silica the next largest constituent. Iron and manganese are present in lesser amounts. Aluminum and copper are detectable but nickel is not.

Crystallographically, the scale consists of a spinel ( $\mathrm{Cr}_{3} \mathrm{O}_{4}$ or some equivalent), a rhombohedral oxide $\mathrm{Cr}_{2} \mathrm{O}_{3}$ with some $\mathrm{Fe}_{2} \mathrm{O}_{3}$ in solid solution, and silica in the $\alpha$-cristobalite form. Grains of elemental metal in the scale are the result of intergranular oxidation of the specimens.

4-Chromium is found to volatilize from the 27 pct $\mathrm{Cr}$ specimens, being observed as $\mathrm{Cr}_{2} \mathrm{O}_{3}$ crystals on the suspension wires and furnace tube. Carbon from the alloy is believed to reduce $\mathrm{Cr}_{2} \mathrm{O}_{3}$ on the outer surface of the scale, some of the resultant elemental chromium volatilizing into the gas stream.

5 - The scaling process is not affected by a change in surface preparation (abraded or electropolished) for the 27 pct $\mathrm{Cr}$ alloy, probably because the oxidation conditions are too severe for this relatively minor variable to have an effect.

\section{Acknowledgment}

The authors wish to thank Mrs. Helen Sheppard and Dr. W. H. Barnes of the Division of Physics for carrying out the X-ray diffraction analyses, and P. E. Beaubien for preparing the metallographic specimens.

\section{References} 48.

${ }^{1}$ J. S. Dunn: Journal Inst. Metals (1931) 46, pp. 25-

${ }^{2}$ K. Heindlhofer and B. M. Larsen: Trans. Amer. Soc. Steel Treat. (1933) 21, pp. 865-895.

${ }^{3}$ A. M. Portevin, E. Pretet, and H. Jolivet: Journal Iron and Steel Inst. (1934) 130, pp. 219-271.

${ }^{4}$ G. Bandel: Arch. Eisenhüttenwesen (1941) 15, pp. 271-283.

${ }^{5}$ M. J. Day and G. V. Smith: Industrial and Engineering Chemistry (1943) 35, pp. 1098-1103.

${ }^{\circ} \mathrm{P}$. Chevenard and X. Wache: Revue Metallurgie (1948) 45, pp. 121-128.

${ }^{7}$ H. M. McCullough, M. G. Fontana, and F. H. Beck: Trans. A.S.M. (1951) 43, pp. 404-420.
${ }^{8}$ R. Griffiths: Journal Iron and Steel Inst. (1934) 130, pp. 377-384.

${ }^{\circ}$ C. A. Siebert and H. G. Donnelly: Trans. A.S.M. (1940) 28, p. 372.

${ }^{10}$ W. H. Hatfield: Journal Iron and Steel Inst. (1927)

115, pp. 483-522.

${ }^{11}$ W. E. Campbell and U. B. Thomas: Trans. Electrochem. Soc. (1947) 91, pp. 623-639.

${ }_{12}$ A. B. Winterbottom: Journal Iron and Steel Inst. (1950) 165, pp. 9-22.

${ }^{13}$ W. O. Milligan and L. Merten: Journal of Physical and Colloidal Chemistry (1947) 51, pp. 521-528.

${ }^{14}$ L. Passerini: Gazz. Chim. Ital. (1930) 60, pp. 544558

${ }^{15}$ N. B. Pilling and R. E. Bedworth: Journal Inst. Metals (1923) 29, pp. 529-582.

${ }^{18}$ R. Griffiths: Iron and Steel Inst. Carnegie Scholarship Memoirs (1937) 26, pp. 165-174.

${ }^{17}$ L. B. Pfeil: Journal Iron and Steel Inst. (1931) 123, pp. 237-258.

${ }^{18}$ B. W. Dunnington, F. H. Beck, and M. G. Fontana: Corrosion (1952) 8, pp. 2-13.

${ }^{10}$ A. F. Wells: Quarterly Reviews (1948) 2, No. 3, pp. 185-202.

${ }^{20}$ O. Krause and W. Thiel: Ber. deutsch. keram. Ges. (1934) 15, pp. 101-110.

${ }_{21}$ I. I. Kornilov and A. I. Spikelman: Doklady Akad. Sci. U.R.S.S. (1946) 54, pp. 511-514.

${ }_{22}^{2}$ D. M. Dovey and I. Jenkins: Journal Inst. Metals (1950) \%6, pp. 581-596.

${ }^{23} \mathrm{~J}$. W. Hickman and E. A. Gulbransen: Trans. AIME (1949) 180, pp. 519-533; Metals Technology (June 1948).

${ }^{24}$ A. E. White, C. L. Clark, and C. H. McCollam: Trans. A.S.M. (1939) 2\%, pp. 125-148.

${ }_{25}^{25}$ B. Lustman: Trans. AIME (1950) 188, pp. 995-996; Journal of Metals (August 1950).

${ }^{28}$ L. S. Darken: Journal Amer. Chem. Soc. (1948) Y0, pp. 2046-2053.

${ }_{27}$ B. Lustman: Metal Progress (1946) 50, pp. 850-860.

${ }^{28}$ C. Wagner: Corrosion and Material Protection

(1948) 5, No. 5, pp. 9-11.

${ }_{20}^{20}$ D. J. M. Bevan, J. P. Shelton, and J. S. Anderson: Journal Chem. Soc. (1948) pp. 1729-1741.

${ }^{30} \mathrm{C}$. Wagner: High Temperature Properties of Metals. (1951) pp. 93-132. A.S.M.

${ }_{31}$ E. M. Mahla and N. A. Nielsen: Trans. Electrochem. Soc. (1948) 93, pp. 1-15.

${ }^{32}$ S. Dushman: Scientific Foundations of Vacuum Technique. (1949) p. 778. New York. John Wiley and Sons.

${ }^{33}$ E. A. Gulbransen, W. S. Wysong, and K. Andrew: Trans. AIME (1949) 180, pp. 565-578; Metals TechNOLOGY (September 1948).

\title{
Technical Note
}

\section{On the Reversal of the Strain-Induced Martensitic Transformation in the Copper-Zinc System}

\author{
by J. E. Reynolds, Jr. and M. B. Bever
}

\footnotetext{
TN several alloys of iron, copper, and lithium as well as in some pure metals, martensite formed

J. E. REYNOLDS, Jr., Junior Member AIME, is Instructor and M. B. BEVER, Member AIME, is Associate Professor, Dept. of Metal. lurgy, Massachusetts Institute of Technology, Cambridge, Mass. TN 124E. Manuscript, June 20, 1952.
}

on cooling reverts to the parent phase upon heating to a temperature below the equilibrium temperature at which the parent phase becomes stable. ${ }^{1}$ These martensitic transformations, therefore, are thermally reversible, although appreciable hysteresis may be involved. The martensitic reaction has long been 